\title{
A TRIZ Approach to Reliable Megaproject Sustainability
}

\author{
Zhen Chen ${ }^{1 *}$, Andrew Agapiou ${ }^{1}$, Heng $L^{2}$ and Qian $X u^{3}$ \\ ${ }^{1}$ Department of Architecture, University of Strathclyde, Glasgow, Scotland, United Kingdom, ${ }^{2}$ Department of Building and Real \\ Estate, The Hong Kong Polytechnic University, Hong Kong, China, ${ }^{3}$ Freelancer, Chongqing, China
}

Purposes: This article presents a recent research into megaproject sustainability with a particular focus on identifying a structure of its body of knowledge so as to establish the methodology of megaproject assessment on sustainability (MAS), which consists of a research roadmap toward megaproject sustainability and a system reliability analysis. In response to the research topic on "Reviews for Advanced Construction Management" at Frontiers in Built Environment, this article aims to make a contribution with the description about a generic approach to conducting literature review based on a whole range of relevant evidence in a systemic way.

Methodology: The research described in this article is underpinned by the use of several methods. The nine-square process (NSP) of Theory of Inventive Problem Solving (TRIZ) is

OPEN ACCESS

Edited by:

Yongkui Li,

Tongji University, China

Reviewed by:

Rebecca Jing Yang,

RMIT University, Australia

Han Lin,

Nanjing Audit University, China

${ }^{*}$ Correspondence:

Zhen Chen

z.chen@live.com

Specialty section: This article was submitted to

Construction Management,

a section of the journal

Frontiers in Built Environment

Received: 07 January 2021

Accepted: 26 April 2021

Published: 22 September 2021

Citation:

Chen Z, Agapiou A, Li H and Xu Q (2021) A TRIZ Approach to Reliable

Megaproject Sustainability.

Front. Built Environ. 7:650699.

doi: 10.3389/fbuil.2021.650699 the method for facilitating a systemic evidence-based learning (EBL) process to identify further research into MAS. A normal process to establish research roadmap was then introduced to summarize what has been identified as specific research tasks alongside lifecycle processes on megaproject delivery, to which RIBA Plan of Work 2020 was adopted as the prototype. An event tree analysis (ETA) was eventually introduced by incorporating the novel measurements on system reliability to support quantitative MAS in terms of both practices and research.

Findings: This article presents several findings from the described research, and these include that the use of NSP led to the formation of a systematic procedure for literature review, a procedure to support MAS, a research roadmap to facilitate efforts to be made for megaproject sustainability, and the feasibility of system reliability analysis to measure the status of sustainability underpinned by research and practices throughout megaproject lifecycle.

Abbreviations: ANP, Analytic Network Process; BIM, Building Information Model/Modelling/Management; BREEAM, Building Research Establishment Environmental Assessment Method; CEDD, Civil Engineering and Development Department (Hong Kong SAR); CIE, International Commission on Illumination; CMBOK, Construction Management Body of Knowledge; COST, Cooperation in Science and Technology (EU); DTI, Department of Trade and Industry (UK); EBL, Evidence-Based Learning; ETA, Event Tree Analysis; HS2, High Speed Two (project); ICCPM, International Centre for Complex Project Management; ICE, Institution of Civil Engineers; IPA, Infrastructure and Projects Authority; IPMA, International Project Management Association; MAS, Megaproject Assessment on Sustainability; MSBOK, The Body of Knowledge for Megaproject Sustainability; NSP, Nine-Square Process; OED, Operations Evaluation Department (The World Bank Group); PRA, Probabilistic Risk Assessment; PMI, Project Management Institute; RIBA, Royal Institute of British Architects; SPeAR ${ }^{\circledR}$, Sustainable Project Appraisal Routine (from Arup); STEEP, Social, Technical, Economic, Environmental and Political (aspects/ issues/risks); TRIZ, Theory of Inventive Problem Solving. 
Implications: The described research provides four modules to foster further research into megaproject sustainability, and these include a TRIZ-based module to facilitate systemic literature review for EBL, a lifecycle process module for MAS, a prototype research roadmap to guide research and development for megaproject sustainability, and an ETA module to support a system reliability analysis in the dynamic process of research and practices toward megaproject sustainability.

Value: The research described in this article has made an initial effort to conduct a strategic review, development, analysis, and discussion about tactics for research and development toward megaproject sustainability. Research findings can be used for related research and practices with regard to technical guidance and best practices in megaproject delivery.

Keywords: assessment, evidence-based learning, megaproject, methodology, research roadmap, review, sustainability, TRIZ

\section{INTRODUCTION}

In the built environment, a megaproject is a large-scale new development or redevelopment project that is typically worth over $\$ 1$ bn and can make gigantic impacts on the society, the economy, and the environment at the local, regional, national, and even international levels in short and longer terms. The sustainability of megaprojects, with regard to their continuous abilities at particular levels throughout lifecycle, is therefore crucial for not only individual but also consensus decisionmaking in both engineering and management sessions across interactive layers and clusters at various project stages.

According to literature review on current professional services, sustainability in megaproject practice is normally measured and reported separately on the social, economic, and environmental aspects on an annual basis in many corporate reports such as those provided by AECOM (2016), Bechtel (2016), Carillion (2016), and Skanska (2016) from the supply side; and the Crown Estate (2016) and the High Speed Two (HS2, 2016) from the client side. The fragments in sustainability reporting through the use of current approaches to assessing megaproject delivery have actually added a new risk with regard to their performance and the value for money at various project stages. The interactions of this risk with all other risks in relation to critical issues on time, cost, quality, etc., can significantly upgrade the level of complexity in project management in response to the strong emphasis on sustainability in megaproject development and operation, and consequently aggravate the consistent problem of overruns on cost and time during construction, and extra resources usage during construction, operation, and redevelopment in the whole life of megaprojects.

While there are discussions worldwide on the need for implementing integrated sustainability reporting at the corporate level, an integrated sustainability measurement for either existing or new megaprojects throughout lifecycle is in need to fill in the gap in the theory and practice of megaproject management in terms of developing and using new advanced techniques for integrated MAS. In response to this need, a new research project on an analytic approach to sustainability assessment in urban megaprojects has been set up recently at the University of Strathclyde, and this article describes the preliminary findings from research into a research roadmap for the technical advancement of MAS in the next decade or longer term.

This article focuses on the description about how such a research roadmap was developed and what has been included in this research roadmap with regard to its usefulness in the integrative measurement of megaproject sustainability at the eight project stages well defined by RIBA (2013) and RIBA (2020) in its latest guide on plan of work. To achieve this goal, this study aims to explore key research areas in MAS so as to draw a technical roadmap to inform further research and practice with regard to making a good contribution to the body of professional knowledge in terms of effectively tackling technical challenges such as cost and time overruns in short and longer terms, effective lessons learning and knowledge use, as well as the coordinated use of building information modeling (BIM) in megaproject practice. In particular, this article presents a new research methodology underpinned by TRIZ (Gadd, 2011), which has been used to explore areas of further research into MAS through evidencebased learning (EBL) (Cranney and McDonald, 2012). The key research findings are described here to draw a technical roadmap for further research and practice into MAS.

It is the initiative of the research described in this article to yield useful outcomes that can support the development of a technical guidance on megaproject sustainability. Therefore, this article consists of descriptions on the following key issues:

- the background detection for research justification,

- the methodology for establishing the research roadmap,

- the framework of the megaproject sustainability body of knowledge,

- the research roadmap toward megaproject sustainability, and

- the system reliability analysis of megaproject sustainability.

\section{BACKGROUND}

A preliminary literature review has been conducted at the early stage of this research to justify the aim and objectives of the 
research so as to establish a concrete background to further deploy research activities. The literature review has focused on two issues, including the assessment of megaproject sustainability, and the development of research roadmaps in related areas. This section describes the findings from this literature review.

\section{Megaproject Sustainability Assessment}

The characteristics of sustainability within megaprojects (typically worth over $\$ 1$ bn each) can make gigantic impacts on the society, the economy, and the environment at the local, regional, national, and even international levels depending on the nature of the project in short and longer terms, and the pursuit of megaproject sustainability in development and operation is to satisfy the need for a sufficient address on dynamically interactive issues relating to social, technical, economic, ecological, and political (STEEP) aspects throughout project lifecycle. Therefore, it is an important but challenging task to do a reliable assessment on the overall sustainability of individual megaprojects to ensure the target is met in practice.

The consideration, decision-making, and actions on megaproject sustainability (Chen, 2018) within an ideal circumstance need to sufficiently address interactive STEEP issues in an effective manner throughout project lifecycle, and the complexity caused by the integrative effects of STEEP forces (Chen, 2010) has therefore continuously made it a challenging task not only in practice to achieve specified sustainability goals but also in research to measure the sustainability in a reliable way.

Academic research into MAS has been gradually developing in the past decade. For example, Chen (2007) explored the use of analytic network process (ANP) as an optioneering technique for sustainability-oriented evaluation among options in a series of experimental case studies on megaprojects, including one of the largest urban regeneration projects, i.e., Liverpool ONE (Chen and Khumpaisal, 2009), three international hub airports in China (Chen, 2010), and the urban light rail project Edinburgh Trams (Boateng et al., 2015); the research described by Sarkheyli et al. (2016) aims at a set of sustainability assessment criteria covering economic, environmental-physical, and sociocultural issues in relation to processes and results in one urban redevelopment project in the Samen District of Mashhad in Iran. It has been found that both qualitative and quantitative methods have been applied in academic research into MAS, and there have been many discussions on key issues such as how to define a suitable set of assessment criteria and what ideal evaluation techniques could be used to make reliable assessment.

The pursuit on sustainability in megaprojects through lifecycle has become more popular in the construction sector. One particular demonstration is the UK Government Construction Strategy 2016-2020, which was recently produced by the Infrastructure and Projects Authority (IPA, 2016) seeking to improve delivery, efficiency, and performance across economic and social infrastructure projects in the public, private, and regulated sectors, and has set up one prioritized area on whole-life approaches to pursuing sustainability in construction. Although there has been no industry-wide tool for MAS at either the work-stage level or the life-cycle level, professional development on sustainability-oriented assessment for construction projects has been continuously growing over the past more than 20 years, for example,

- the BREEAM (Building Research Establishment Environmental Assessment Method) (BRE, 2016) for the assessment of buildings and infrastructures at main work stages covering new build, operation, and refurbishment;

- the sustainability checkpoints specified for individual work stages in RIBA (2013) Plan of Work; and

- the SPeAR ${ }^{\circledR}$ (Sustainable Project Appraisal Routine) (Arup, 2012), which is the tool used by sustainability consultants and sustainable buildings and sustainable infrastructure designers at Arup for sustainability appraisal to support decision-making and communicate in project development.

In the meantime, there are many sustainability-oriented industry awards prompting best practices in the construction sector at the global scale each year. These professional initiatives have demonstrated that it has been widely accepted by the construction industry across the world that sustainability is essential for projects no matter which stage they might be at, and it has become a necessary part of work to pursue sustainability toward specified levels in all types of projects including new construction, reconstruction, and redevelopment projects. From this point of view, there is an anticipated demand for tools for MAS to support better decisionmaking by professionals at either engineering or management positions to work toward specified milestones in accordance with the sustainability checkpoints specified by RIBA (2013) throughout project lifecycle. It is therefore a research task to develop work stage-oriented tools for MAS.

\section{Need for Research Roadmap}

It is an assumption of the described research that milestones can be established in accordance with all the main work stages specified with the sustainability checkpoints given by RIBA (2013), and these main work stages can include Redevelopment, in the context of decommissioning or recommissioning, as the last work stage of project lifecycle in addition to the currently specified work Stages 0 to 7 by RIBA (2013) and RIBA (2020). These milestones, which should therefore include nine main ones for individual work stages (see the section on Research Roadmap below) can be dependable in terms of sustainability goals in the process to develop a research roadmap for MAS, although there might be some alternations to be made for specific sustainability checkpoints through either modifying the existing ones or adding new ones to reflect the nature of megaprojects, which are normally different from small projects. To establish the nine main milestones of megaproject sustainability onto a research roadmap, a further literature review was conducted to find answers to two essential questions:

- Q1 on whether there is already such a research roadmap for MAS, and 
- Q2 on what a new research roadmap for MAS should cover.

The answers to the two questions above can further justify the need for and the contents of the described research.

To find the answer to Q1, there are two checking points upon the publication of this article, and the following two combined search terms are used to identify relevant academic research and professional practices on Google:

- Search term A: "mega project" AND sustainability AND "research roadmap," and

- Search term B: megaproject AND sustainability AND "research roadmap."

The first checking point is on June 30,2017, and the answer to Q1 was simply a null set according to the results returned from Google. The second checking point is on April 4, 2021, and the answer to Q1 was also negative despite new results (see Table 1) against the previous null set according to the results returned from Google.

According to the search results collected at the second checking point, it looks there is an increase in terms of the information related to megaproject, sustainability, and research roadmap; however, it is also found that research into either sustainability assessment or megaproject sustainability with regard to research roadmap was only conducted by Chen and Agapiou (2017) on the preliminary of the research described in this article, and there is no other reference to improve the established research roadmap.

It was therefore assumed that the described research into MAS for a research roadmap has its originality to make a contribution to the body of knowledge of megaproject sustainability, which is one important part of professional practice on megaprojects.

To find the answer to the second question, the literature review was conducted to look into representative research roadmaps developed in related areas. The following research roadmaps were reviewed regarding their structures and contents in specific areas:

- Arup (2013) Research Roadmap 2013,

- BSRIA (2015) The BIM Roadmap: A Building Owner's Guide to Implementing BIM,

- CIE (2016) Research roadmap for healthful interior lighting applications,

- DTI (2007) Roadmap for the development of intelligent monitoring of concrete structures,

- ICCPM (2011) Global Perspectives and the Strategic Agenda to 2025.

It has been found from the review into these research roadmaps that the generic contents that need to be considered and covered include research themes and areas, and research timescale and milestones. As a result, the findings on the generic format adopted in research roadmaps have provided useful information for developing a new research roadmap for MAS.

The literature review into megaproject sustainability assessment and research roadmaps has justified the need for a new research roadmap for MAS. It has been identified that the new research roadmap will need to specify research themes and areas in relation to sustainability assessment in megaprojects throughout the lifecycle, and it is also necessary for the research roadmap to clarify the timescale to achieve milestones set up for MAS.

\section{METHODOLOGY}

\section{Research Strategy}

The strategy made for the research described in this article focuses on the aim and objectives of research and the methodology to ensure the use of appropriate methods to derive reliable outcomes. The literature review conducted for this research has focused on the assessment of megaproject sustainability and the need for planning on the development of innovative solutions with clear identities on a research roadmap so as to improve sustainability-oriented practice in megaprojects, and this has eventually led to this research into a roadmap for a comprehensive understanding and guide of further research relating to MAS, which also has numerous connections to other tasks throughout the whole life of megaprojects. The research toward such a roadmap was conducted through considering the following three objectives:

- To identify a set of research areas through a comprehensive literature review to form the theoretical framework of the body of knowledge for MAS.

- To draw a research roadmap of MAS by connecting all identified research areas in related sustainability domains into a reliable work procedure.

- To specify technical details of MAS at different work stages alongside the chosen work procedure such as RIBA Plan of Work 2020.

To achieve the goal of this research, a set of research methods was used. The preliminary research findings described here have been derived through the use of TRIZ integrated with EBL and system analysis and design. An extensive literature review sustained by TRIZ was used to justify research aim and objectives as well as essential research themes and areas to establish a framework of the body of knowledge for megaproject sustainability (MSBOK). A process on system analysis and design was then used to derive a research roadmap for MAS, and this includes a technical framework as the procedure of MAS, and its related research tasks in short, medium, and long terms. It was considered when the research roadmap was developed to reflect the progress of current research and practice with regard to the best practice in related areas for megaproject sustainability.

\section{TRIZ-led Evidence-Based Learning}

TRIZ as a useful tool to establish a comprehensive understanding of problem under solving was chosen as a research method to identify themes and specific areas so as to form the research roadmap. TRIZ is the Russian acronym for "Teoriya Resheniya 
Izobretatelskikh Zadatch" and means the "Theory of Inventive Problem Solving" in English. It was developed in 1946 by the Soviet inventor Genrich Altshuller and his colleagues (Gadd, 2011), and has widely been adopted in many industry sectors. For research in the built environment, TRIZ has been introduced in the past decade. For example, an integration of TRIZ with ANP for the multicriteria assessment of façade systems with regard to the whole life value of the design (Chen et al., 2007), a holistic literature review approach underpinned by TRIZ to forming a technical framework of facilities management with regard to the body of knowledge and the principles (Chen, 2017). These researches have informed further research into areas where a comprehensive literature review is in need to derive the scope and directions of further research. In this regard, the TRIZ was chosen for the research described in this article with a particular focus on essential themes and related areas of a research roadmap for MAS.

The literature review on knowledge-driven assessment for the sustainable built environment indicated a lack of research into EBL to support decision-making in lifecycle-oriented facilities management and the necessity of new research to bridge over the gap between EBL and knowledge-driven multicriteria assessment for the design (Clipson and Johnson, 1987) and management (Kovner and Rundall, 2006). In this regard, the EBL was adopted to support reliable and consistent assessment in developing the research roadmap for MAS. The integrative use of these methods in this research has shown effectiveness in identifying research themes and areas to establish a new research roadmap for MAS.

In the field of MAS, it has been of both academic interest in and professional need for specifying the MSBOK to support best practice in research and services on megaprojects. To derive a reliable set of MSBOK through an extensive review on the literature and practice, and to verify its suitability to clustered research themes and areas at individual work stages and the whole life of megaprojects, the TRIZ was chosen to facilitate an expected inventive process to establish the framework and elements of MSBOK. For such a dedicated research, the ninesquare process (NSP), which is one practical TRIZ tool, was chosen to qualitatively identify and justify the framework of MSBOK and the clusters of research tasks.

Figure $\mathbf{1}$ is the diagram illustrating nine squares, which are also called windows in this article, that were named and used to derive the MSBOK framework and the research tasks described in this article. In principle, the NSP looks on the horizontal direction into the history, the present, and the future of the problem to be solved through a review into related information at the microcosmic and macroscopic levels as well as the system level across the vertical direction. Based on the theory of the NSP, Figure 2 presents an evolutionary process to derive the terminal goal through a middle window which collects all the findings from the rest of the seven windows. As illustrated in Figure 1, the window of MAS was set up as the goal of this nine-window analytic process and achieved through the establishment of MSBOK in the middle window to collect feedback from the other seven windows based on evidence-based review.

An overview with further descriptions about these nine windows is presented in Table 2.

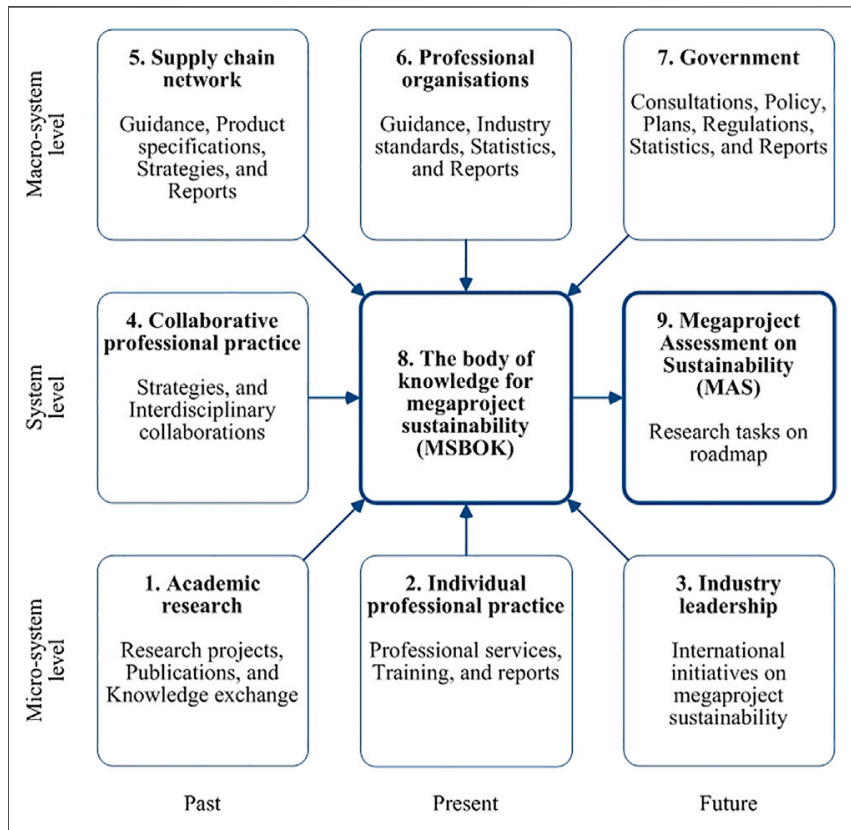

FIGURE 1 | A TRIZ approach to identifying research areas for MAS.

TABLE 1 | Search results from Google and the Web of Science as of April 4, 2021.

Search terms

Search engines

\begin{tabular}{cccc}
\cline { 2 - 3 } & Google & Google Scholar & $\begin{array}{c}\text { Web of Science } \\
\text { (all databases, 1864-2021) }\end{array}$ \\
\hline A & 240 & 26 & 0 \\
\hline B & 952 & 54 & 0 \\
\hline C & 212 & 5 & 0 \\
\hline D & 9 & 5 & 0
\end{tabular}

Notes: 1. Search term A: "mega project" AND sustainability AND "research roadmap." 2. Search term B: megaproject AND sustainability AND "research roadmap." 3. Search term C: megaproject AND "sustainability assessment" AND "research roadmap." 4. Search term D: "megaproject sustainability" AND "research roadmap."

It is expected that this dedicated review can ensure a systematic study on MSBOK from the past through present to the future at three main levels on microsystem, system, and macrosystem in the scope of MAS-related practice and research, and derive useful solutions of the knowledge framework of MSBOK and the clusters of research tasks for MAS.

\section{KNOWLEDGE FRAMEWORK}

For the framework of MSBOK, this research has identified three knowledge domains across five research themes through the TRIZdriven literature review described above. The three knowledge domains include the built environment, the social environment, and the natural environment, which are recognized as critical technical domains relating to MAS. The five research themes 


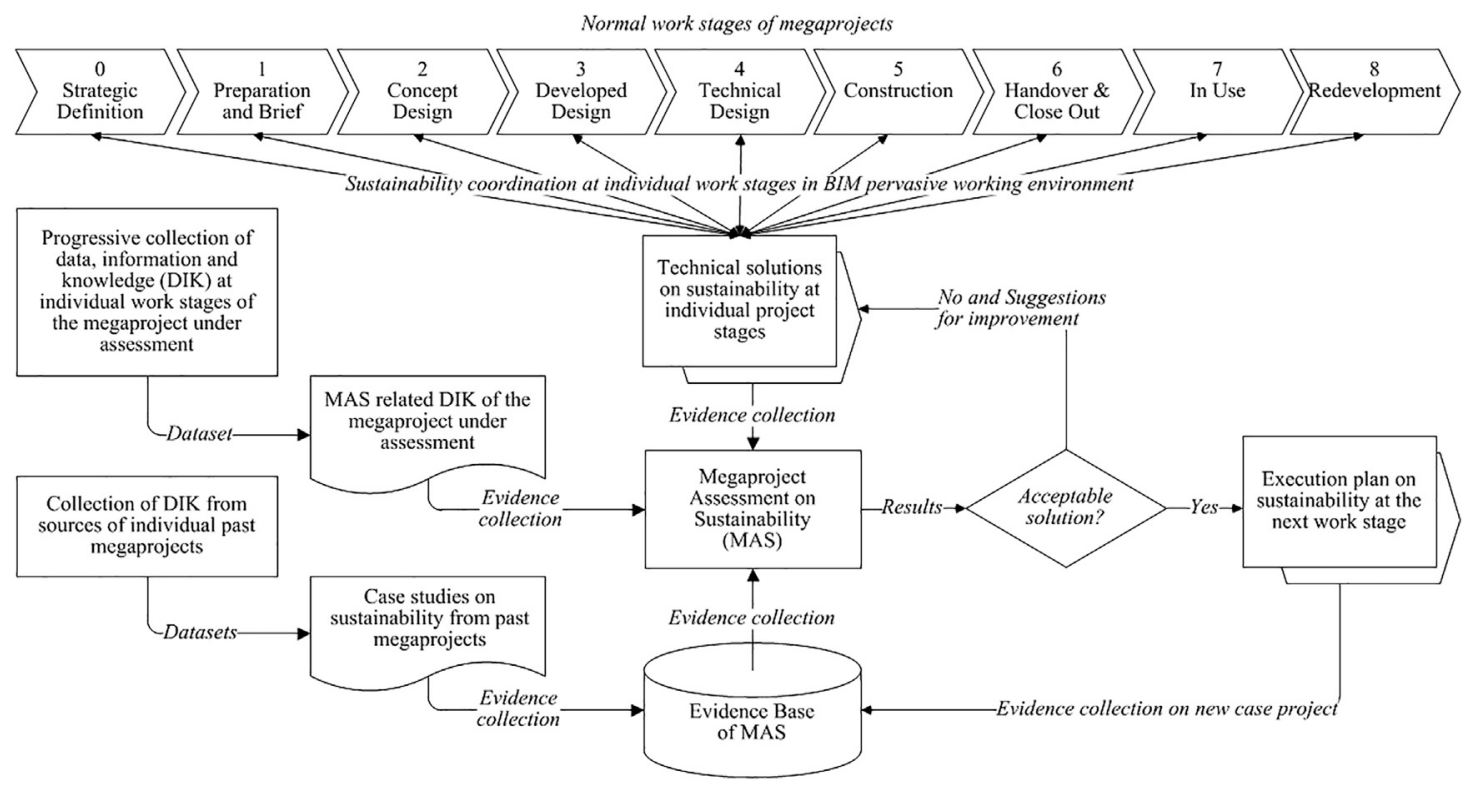

FIGURE 2 | An illustrated procedure of MAS.

focus on social issues, technical issues, economic issues, environmental issues, and political issues, that is, STEEP issues, in megaproject development and management when sustainability is under consideration across the whole life. Table 3 provides a matrix to summarize the themes and associated areas of research for MAS within the framework of MSBOK, for which all the identified research areas are allocated across three domains and five themes. The findings from the TRIZ-driven process of literature review have identified key areas of research for MAS, and these findings were further used to design research tasks to establish the research roadmap to achieve the nine milestones indicated in response to sustainability checkpoints at nine work stages specified by RIBA (2013) and RIBA (2020).

\section{RESEARCH ROADMAP}

The procedure of MAS is a series of connected actions to be taken at individual work stages in the whole project life to achieve the particular milestones on sustainability assessment in megaprojects. Figure 2 illustrates a generic procedure of MAS underpinned by EBL with integration with a normal plan of work (RIBA, 2013; RIBA, 2020) for megaprojects. It has been used to develop the research roadmap according to outlined processes across project work stages, and can be used as a roadmap to inform further research activities in related themes and areas summarized in Table 3 through a TRIZ-driven literature review.

TABLE 2 | An overview of nine processes/windows for EBL.

\section{Processes/Windows}

1. Academic research

2. Individual professional practice

3. Industry leadership

4. Collaborative professional practice

5. Supply chain network

6. Professional organizations

7. Government

8. MSBOK

9. MAS

\section{Descriptions}

The review focuses on research projects, publications, and knowledge exchange activities.

The review focuses on professional services, training, and reports.

The review focuses on international initiatives on megaproject sustainability.

The review focuses on strategies, and interdisciplinary collaborations.

The review focuses on guidance, product specifications, strategies, and reports at the macro-system level.

The review focuses on guidance, industry standards, statistics, and reports at the macro-system level.

The review focuses on consultations, policy, plans, regulations, statistics, and reports at the macro-system level.

A framework of the body of knowledge for megaproject sustainability.

Research tasks specified for R\&D in megaproject sustainability. 
TABLE 3 | MAS-oriented research themes and areas within MSBOK framework.

\section{STEEP themes}

(Chen and Li, 2006; Chen,

2010; Boateng et al.,

2017)

\section{Social issues}

Technical issues

Economic issues

Environmental issues

Political issues
Environmental domains and areas of research

(Altshuler and Luberoff, 2003; Merrow, 2011; Greiman, 2013;

Priemus and Van Wee, 2013; Hart, 2015; Flyvbjerg, 2017)

$\begin{array}{lll}\text { 1. Built environment } & \text { 2. Social environment } & \text { 3. Natural environment }\end{array}$

1. Built environment

2.1 Social activities

3.1 Social interactions

1.1 Social need

2.2 Technical usefulness

3.2 Technical interactions

2.3 Economic value

3.3 Economic risks

1.3 Economic performance

2.4 Environmental concerns

3.4 Environmental degradation

1.4 Environmental impacts

1.5 Political impacts
3.5 Political interactions

TABLE 4 | Strategic description about outcome-driven research tasks for MAS.

\begin{tabular}{|c|c|c|c|}
\hline \multirow{2}{*}{$\begin{array}{l}\text { Research } \\
\text { outcomes }\end{array}$} & \multicolumn{3}{|c|}{ Time scales and focuses for research into MAS } \\
\hline & $\begin{array}{l}\text { Short term (ST) } \\
\text { (Less than } 5 \text { years) }\end{array}$ & $\begin{array}{l}\text { Medium term (MT) } \\
\text { (5-10 years) }\end{array}$ & $\begin{array}{l}\text { Long term (LT) } \\
\text { (More than } 10 \text { years) }\end{array}$ \\
\hline Models & $\begin{array}{l}\text { Developing models } \\
\text { - Defining evaluation criteria } \\
\text { - Choosing individual evaluation techniques } \\
\text { - Developing individual models }\end{array}$ & $\begin{array}{l}\text { Improving models: } \\
\text { - Refining evaluation criteria. } \\
\text { - Improving individual models }\end{array}$ & $\begin{array}{l}\text { Improving models } \\
\text { - Developing individual evaluation } \\
\text { techniques. }\end{array}$ \\
\hline Toolkits & $\begin{array}{l}\text { Consideration on toolkits } \\
\text { - Considering the interactions between models, and } \\
\text { their integration to form toolkits } \\
\text { - Considering the functions of toolkits to be supported } \\
\text { by models }\end{array}$ & $\begin{array}{l}\text { Developing toolkits } \\
\text { - Defining the functions of toolkits, and the } \\
\text { interactions between models } \\
\text { - Developing individual toolkits }\end{array}$ & $\begin{array}{l}\text { Improving toolkits } \\
\text { - Improving the functions of toolkits, and } \\
\text { the interactions between models } \\
\text { - Improving individual toolkits }\end{array}$ \\
\hline Systems & $\begin{array}{l}\text { Consideration on systems } \\
\text { - Considering the interactions between models, and } \\
\text { their integration in toolkits to form systems } \\
\text { - Considering the functions of systems }\end{array}$ & $\begin{array}{l}\text { Consideration on systems } \\
\text { - Considering the interactions between toolkits, } \\
\text { and their integration to form systems } \\
\text { - Considering the functions of systems }\end{array}$ & $\begin{array}{l}\text { Developing systems } \\
\text { - Defining the functions of systems, and the } \\
\text { interactions between toolkits } \\
\text { - Developing individual systems }\end{array}$ \\
\hline Case studies & Applications of models & Applications of toolkits & Applications of systems \\
\hline
\end{tabular}

The procedure of MAS as illustrated in Figure 2 consists of several key elements, including a chain of normal work stages of megaprojects, a set of technical solutions yielded at individual work stages, the process of sustainability assessment, and the support of an evidence base. Although it could be deemed as an ideal plan of work for megaproject sustainability throughout the lifecycle, the implementation of such a plan of work needs sufficient support from not only professionals working on sustainability in megaproject practice but also academics doing research into useful tools such as models, toolkits, and systems for sustainability assessment. Research focusing on the key elements of the procedure of MAS is at the position to facilitate its implementation in megaproject practice, and the MAS-oriented research is further described below in specific research tasks and targeted outcomes with regard to an overall support to MAS in practice in longer term.

\section{RESEARCH TASKS}

The research to support the implementation of MAS according to the illustrated procedure in Figure 2 needs to focus on several key tasks to achieve targeted outcomes that are useful in the practice on megaproject sustainability. A strategic description about research tasks and their outcomes for MAS is given in Table 4, which summarizes, in a matrix format, the authors' perceptions on the essentials of MAS-oriented research at various time scales, and was based on research themes and areas identified from the TRIZ-driven literature review and evidence-based learning.

The main tasks of research into MAS, as described in Table 4, have been allocated into three time periods: short term, medium term, and long term. Highlighted research work to be done during these three terms is described later.

For the short term, which is the fast pace, the research into MAS is expected to focus on developing models that can be used to conduct reliable assessment on specific targets on either specific or overall aspects relating to STEEP issues at individual work stages, and research work will need to deal with key technical issues such as assessment criteria, evaluation techniques, and useful tools, that is, models for MAS through experimental case studies; in addition, research work during this term will also need to consider how models developed at the initial time period can still be useful in the longer term with regard to their integrations with toolkits and systems for assessment. 
TABLE 5 | Clusters of research tasks for MAS in the short term.

Project stage-clusters and sustainability milestones

M1 Planning

M1.1 Assessment of strategy

M1.2 Assessment of preparation and brief

\section{Short-term (ST) tasks for research into MAS}

ST1 Defining criteria to evaluate project strategies, specifications, feasibility, etc.

ST2 Developing evaluation models for possible usage by developers and local authorities ST3 Collecting evidence for MAS at planning stage

ST4 Defining criteria to evaluate architectural and engineering design with specifications ST5 Developing evaluation models for possible usage by designers, other contractors, and developers ST6 Collecting evidence for MAS at design stage
M2.1 Concept design assessment

M2.2 Developed design assessment

M2.3 Technical design assessment
ST7 Defining criteria to evaluate construction strategies, plans, activities, resources usages, etc. ST8 Developing evaluation models for possible usage by construction contractors and developers ST9 Collecting evidence for MAS at construction stage

M3.1 Assessment of construction

M3.2 Assessment of handover

ST10 Defining criteria to evaluate operation strategies, plans, activities, resources usages, etc. ST11 Developing evaluation models for possible usage by developers and/or owners ST12 Collecting evidence for MAS at operation stage

M4.1 Assessment of operation

M4.2 Assessment of maintenance

ST13 Defining criteria to evaluate redevelopment strategies, plans, activities, resources usages, etc.

M5 Redevelopment

M5.1 Assessment of decommission

M5.2 Assessment of recommission

ST14 Developing evaluation models for possible usage by developers and redevelopment contractors ST15 Collecting evidence for MAS at redevelopment stage

TABLE 6 | Clusters of research tasks for MAS in the medium term.

Project stage-clusters and

sustainability milestones

\section{M1 Planning}

M1.1 Assessment of strategy

M1.2 Assessment of preparation and brief

\section{Medium-term (MD) tasks for research into MAS}

MT1 Improving criteria and models to evaluate project strategies, specifications, feasibility, etc.

MT2 Developing evaluation toolkits for developers and local authorities

MT3 Collecting more evidence for developing an evidence base for MAS at the planning stage

\section{M2 Design}

M2.1 Concept design assessment

M2.2 Developed design assessment

M2.3 Technical design assessment
MT4 Improving criteria and models to evaluate architectural and engineering design with specifications MT5 Developing evaluation toolkits for possible usage by designers, other contractors, and developers MT6 Collecting more evidence for developing an evidence base for MAS at the design stage

\section{M3 Construction}

M3.1 Assessment of construction

M3.2 Assessment of handover
MT7 Improving criteria and models to evaluate construction strategies, plans, activities, resources usages, etc. MT8 Developing evaluation toolkits for possible usage by construction contractors and developers MT9 Collecting more evidence for developing an evidence base for MAS at the construction stage
M4 Operation

M4.1 Assessment of operation

M4.2 Assessment of maintenance
MT10 Improving criteria and models to evaluate operation strategies, plans, activities, resources usages, etc. MT11 Developing evaluation toolkits for possible usage by developers and/or owners MT12 Collecting more evidence for developing an evidence base for MAS at the operation stage

\section{M5 Redevelopment}

M5.1 Assessment of decommission

M5.2 Assessment of recommission
MT13 Improving criteria and models to evaluate redevelopment strategies, plans, activities, resources usages, etc. MT14 Developing evaluation toolkits for possible usage by developers and redevelopment contractors MT15 Collecting more evidence for use at the redevelopment stage
For the medium term, the research into MAS is expected to focus on a continuous all-round improvement of models developed already, in addition to developing toolkits that are integrations of developed modules that have functions allocated in technical clusters in relation to various work stages, and consideration on how toolkits under development can still be useful in the longer term with regard to their integrations with systems for assessment. Moreover, an evidence base will be ideally developed during this time period toward computer-aided assessment, and it could rely on a commercial software tool at an initial stage.

For the long term, the research into MAS is expected to focus on continuous all-round improvements of models and toolkits developed already, in addition to developing systems that are integrations of models as well as toolkits including the evidence base toward developing a powerful tool for assessment.

For case studies, the research into MAS is expected to focus on continuous tests of tools including models, toolkits, and systems developed at individual time periods, and trying to find problems and potentials for further improvement through experiments on case projects.

The general view on research tasks and outcomes over the three time periods described above is to outline what research can do to support implementing the procedure of MAS. Due to the constraints on available resources for research, there will be a 
TABLE 7 | Clusters of research tasks for MAS in the long term.

Project stage-clusters

and sustainability milestones

M1 planning

M1.1 Assessment of strategy

M1.2 Assessment of preparation and brief

\section{Long-term (LT) tasks for research into MAS}

LT1 Improving models and toolkits to evaluate project strategies, specifications, feasibility, etc.

LT2 Developing evaluation systems for possible usage by developers and local authorities

LT3 Developing an evidence base for MAS at the planning stage

\section{M2 design}

M2.1 Concept design assessment

M2.2 Developed design assessment

M2.3 Technical design assessment
LT4 Improving models and toolkits to evaluate architectural and engineering design with specifications LT5 Developing evaluation systems for possible usage by designers, other contractors, and developers LT6 Developing an evidence base for MAS at the design stage

\section{M3 construction}

M3.1 Assessment of construction

M3.2 Assessment of handover
LT7 Improving models and toolkits to evaluate construction strategies, plans, activities, resources usages, etc. LT8 Developing evaluation systems for possible usage by construction contractors and developers LT9 Developing an evidence base for MAS at the construction stage

M4 operation

M4.1 Assessment of operation

M4.2 Assessment of maintenance

LT10 Improving models and toolkits to evaluate operation strategies, plans, activities, resources usages, etc. LT11 Developing evaluation systems for possible usage by developers and/or owners LT12 Developing an evidence base for MAS at the operation stage

M5 redevelopment

M5.1 Assessment of decommission

M5.2 Assessment of recommission

LT13 Improving models and toolkits to evaluate redevelopment strategies, plans, activities, resources usages, etc. LT14 Developing evaluation systems for possible usage by developers and redevelopment contractors LT15 Developing an evidence base for MAS at the redevelopment stage

long way to achieve the goal of long-term research that can provide an integrated assessment tool at the system level. With regard to identified need for MAS, it is therefore necessary to specify all research tasks and expected outcomes at individual work stages so that the time length of knowledge exchange from research to practice can be reduced. Based on this consideration, the outcomedriven research tasks described in Table $\mathbf{4}$ are further grouped into five clusters of small research tasks for immediate usages at individual work stages.

To specify details of research activities alongside the three time scales, the research tasks specified in Table $\mathbf{4}$ are then grouped into five technical domains, including Planning, Design, Construction, Operation, and Redevelopment, in accordance with the main identical project stages (see Figure 2), and a research roadmap can therefore be developed by setting up milestones alongside the five stage clusters including

- Stage Cluster 1 Planning, which includes Stages 0 and 1;

- Stage Cluster 2 Design, which includes Stages 2 to 4;

- Stage Cluster 3 Construction, which includes Stages 5 to 6;

- Stage Cluster 4 Operation, which is the same to Stage 7; and

- Stage Cluster 5 Redevelopment, which is the same to Stage 8.

Details about the five stage clusters of research tasks for MAS are given in Tables 5 to 7 .

With regard to megaproject sustainability, it is necessary to include Redevelopment, as one particular work stage in the lifecycle of capital project development. As mentioned in Need for Research Roadmap, the scope of redevelopment work is to include decommissioning or recommissioning of the built environment at the final stage of a new megaproject development, and the inclusion of Redevelopment stage in MAS is to complete an entire project landscape and to facilitate the analysis on whole life value (IPA, 2020). The incorporation of Redevelopment as one main project stage, which has not been clearly or formally specified by RIBA (2020) alongside its eight work stages of the Plan of Work at present, is based on considering the necessity to close the loop of megaproject development in the circular economy via a holistic approach to a sustainability-oriented project delivery system (Roaf et al., 2003; Chen et al., 2017; McNaughton et al., 2020). In addition to these strategic considerations, current research such as an ANP experiment for demolition plan evaluation (Chen et al., 2014) also demonstrated the viability to include Redevelopment into a whole life-oriented MAS. It is therefore for the described research to add Redevelopment as a main project stage into descripting the research roadmap for megaproject sustainability.

\section{DISCUSSIONS}

\section{Research Scope}

The description about the research into a research roadmap for megaproject sustainability in this article focuses on two issues, including the first one about research themes and related areas, and the second one about specific research tasks, and the solutions put forward in this article consider the process chain consisting of individual work stages of megaproject lifecycle, and the nature of a BIM pervasive working environment for development and redevelopment of the built environment. Besides its originality in the subject field of megaproject sustainability, the research roadmap was built upon a novel procedure of MAS in connection with megaproject practice. The purpose to develop a procedure for MAS was to ensure that the research roadmap can reflect true need for and real-world requirements on sustainability assessment in megaproject practice across all work stages. From this point of view, the research roadmap presented here has achieved the goal and has a good potential on its usefulness in further research and development. 
In the described research, both work stages, as for the depth of research in terms of processes to be considered on technical issues, and time scale, as for the length of research in terms of time to be used for technical solutions, have been considered to develop the research roadmap for megaproject sustainability. A short discussion about the two scopes is given below.

Lifecycle stages. The five clusters of research tasks (see Tables 5 to 7) have been specified under four types of research outcomes (see Table 4) to fulfill the need for practical tools and evidence to justify their usefulness. All types of research outcomes including models, toolkits, and systems for MAS and case studies using these tools were targeted with a thorough consideration on their necessary connections to all identified research themes and related areas alongside the nine milestones to achieve sustainability in megaproject delivery. From this point of view, the research roadmap described in this article can provide a comprehensive coverage to various demands for excellent practice-oriented deliverables through research advancement with this research roadmap.

Time scale. The time scale of research for MAS has been divided into three parts, including short term for research efforts within five years, medium term for research efforts between five and ten years, and long term for research efforts for more than ten years. This time-oriented arrangement for research development alongside research milestones has been adopted in many research roadmaps in the past according to the authors' observations via literature review, and has also been adopted in developing the new research roadmap via the use of NSP under TRIZ (see Figure 1) at the professional level for its usefulness in megaproject practices. In setting up this time scale, actions (i.e., research tasks) and deliverables specified for this research roadmap have therefore been allocated under a thorough consideration against workloads and achievability. From this point of view, the research roadmap developed from this research has demonstrated a practical meaning as a guide for further research into megaproject sustainability assessment.

\section{Megaproject Sustainability Dynamics}

There are two assumptions made for the research described in this article with regard to the need for the following:

- the achievement of sustainability, that is, megaproject sustainability, and

- the consideration of dynamics, that is, megaproject dynamics.

A short discussion about the two assumptions is given below.

An assumption is made for MAS in terms of sustainability in the whole life of a megaproject. The term "megaproject sustainability" (Chen, 2018) was put forward at the Institution of Civil Engineers (ICE) in 2016 to promote research and practices in megaproject delivery with regard to sustainability considering STEEP issues. It has been further noticed that "project sustainability" (OED, 1988; Bamberger and Cheema, 1990; Morfaw, 2014; Martens and Carvalho, 2016; Aarseth et al., 2017; Khatiwada, 2017; Gijzel et al., 2020; Mansell et al., 2020) as a technical term has been introduced in the subject field of project management across industry sectors since the 1980s, and it has been widely explored on STEEP dimensions in the context of theoretical descriptions and case studies at various project stages. For megaproject, sustainability has also been recognized by leading practitioners (Suárez et al., 2012; Abadie, 2020) as an essential for capital project delivery. A preliminary literature review via NSP (see Figure 1) within the research described in this article shows the importance to establish a lifecycle view of project sustainability, especially in megaproject delivery, and the need for more delicate sustainability assessment. It is therefore expected that MAS is a timely topic in developing the theory and practices of megaproject sustainability in the built environment.

Another assumption is further made for MAS in terms of the general dynamic status of sustainability in the whole life of a megaproject. According to a preliminary literature review via NSP (see Figure 1), publications from research into either "dynamic sustainability" or "sustainability dynamics" are emerging in the context of megaproject management in the past about ten years, and relevant dynamic issues tackled in published research include but not limited to

- project dynamics and sustainability (ICCPM, 2011; IPMA, 2011),

- urban regeneration (Laprise et al., 2015),

- organizational citizenship behavior (OCB) (Wang et al., 2018),

- official development assistance (ODA) (Lee and Jeon, 2018),

- construction supply chain (Pryke, 2019),

- STEEP risks (Chen et al., 2019),

- patterns of circular transition (Haezendonck and Van den Berghe, 2020).

It has been learned from current research into dynamic megaproject management with regard to the sustainability that "megaproject sustainability dynamics" can be introduced as a new technical term that describes the dynamic whole-life status and processes of megaproject development. This lifecycle-oriented new term as a concept has become fundamental here to develop the research roadmap toward megaproject sustainability.

\section{Event Tree Analysis}

It is also an attempt in the described research to further illustrate the research roadmap with an event tree diagram, and this diagram can enable an overall view on routes to sustainability across work stages in megaproject delivery. Figure 3 is an event tree diagram based on the identified research themes and tasks summarized in Tables 5 to 7. This event tree gives a vivid illustration about the research roadmap being discussed in this article. A further description about three layers of this event tree is given below in terms of the goal, gates, and events for megaproject sustainability.

Goal. This event tree is to support an inductive analysis regarding how well the goal on megaproject sustainability can be achieved. This analytical diagram can be further used to conduct a probabilistic risk assessment (PRA) under the situation that megaproject delivery is within a dynamic environment, and it is crucial to ensure an appropriate level of reliability against STEEP risks in megaproject delivery.

Gates. There are five gates set up on the research roadmap shown in this event tree. The five gates are in accordance with the 


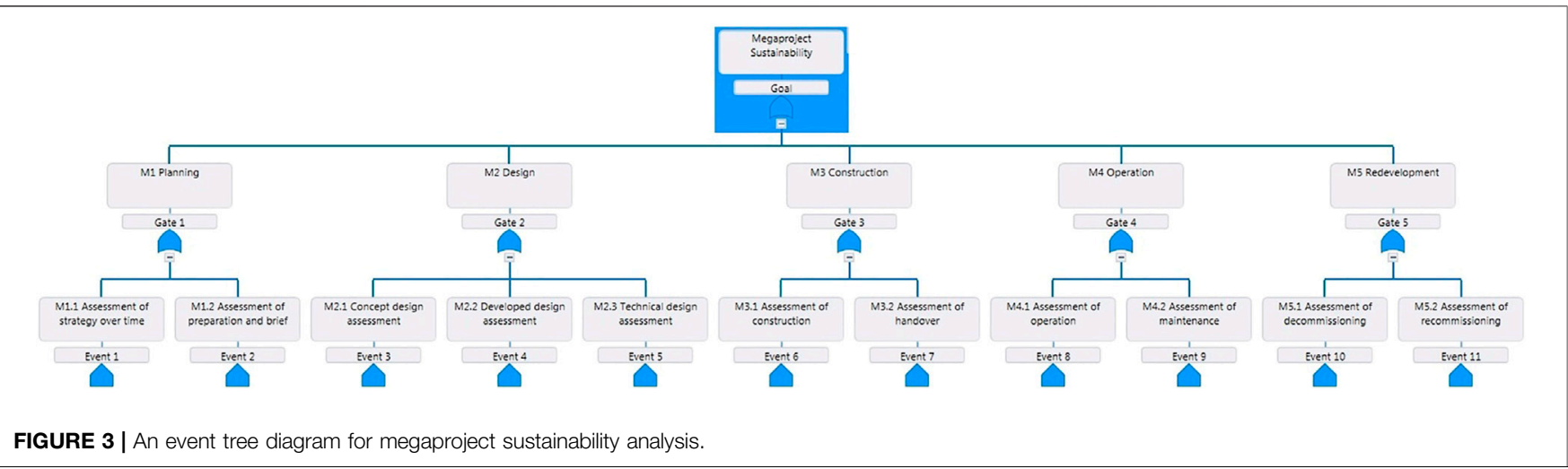

five stage clusters covering Planning, Design, Construction, Operation, and Redevelopment in a connected process sequence. These gates represent gateways from specific sustainability milestones to sustainability goals via MAS at various work stages, and these include the following:

- Gate 1 from 2 milestones at the planning stage,

- Gate 2 from 3 milestones at the design stage,

- Gate 3 from 2 milestones at the construction stage,

- Gate 4 from 2 milestones at the operation stage, and

- Gate 5 from 2 milestones at the redevelopment stage.

It is anticipated that, for one megaproject, the overall goal on sustainability can be measured by a combination of the evaluation of individual goals upon the achievement of 11 milestones on this event tree, which is derived from the identified research roadmap. Therefore, the described research roadmap can also facilitate MAS by using the event tree diagram.

Two calculations can be conducted by using the event tree for megaproject sustainability. The first calculation is to derive an overall sustainability score of one megaproject under assessment, and the second calculation is to measure the reliability of the megaproject under assessment in terms of its achievement of sustainability with the calculated score. Therefore, two equations below are proposed.

Regarding the two measurements on megaproject sustainability via the event tree diagram, Eq. 1 is proposed for milestone-based measurement on the score of megaproject sustainability, while there are other approaches such as ANP to sustainability assessment, and based on previous research into the adoption of system reliability analysis for construction management (Chen, 1995), Eq. 2 is proposed for milestonebased measurement on the reliability of megaproject sustainability under a specific score.

$$
\begin{aligned}
& M S=\sum_{i=1}^{n} M S_{i} \\
& S R=\prod_{i=1}^{n} M R_{i}
\end{aligned}
$$

- MS represents the overall sustainability score of one megaproject under assessment.

- $M S_{i}$ represents the subscore of sustainability upon milestone $i$ across work stages on megaproject lifecycle. The scale of a subscore can be either $[0,10]$ or $[0,100]$.

- $S R$ represents the overall reliability (\%) to achieve the overall sustainability goal that one megaproject under assessment could achieve.

- $M R_{i}$ represents the reliability (\%) to achieve sustainability goal upon milestone $i$ across work stages on megaproject lifecycle. The scale of each reliability value is a decimal within interval $[0,1]$ and can be converted into a percentage.

- $i$ represents the sequence number of sustainability milestone.

- $n$ is the total number of sustainability milestones, and it is 11 according to the event tree.

Events. A series of events is connected with the 11 sustainability milestones on the event tree diagram. These events are associated with the research tasks specified in Tables 5 to 7. According to what has been summarized in the three tables, three events are specified for each sustainability milestone at one time scale. It is therefore anticipated that the arrival at each sustainability milestone can be further measured by considering the reliability of triple events.

Regarding the two above-mentioned equations to measure the status of megaproject sustainability via the event tree diagram, two more equations are proposed by incorporating the measurement of events. For the score of sustainability, Eq. 3 is proposed for research task-driven event-specific measurement of individual milestones for megaproject sustainability, and for the reliability of sustainability, Eq. 4 is proposed for event-specific measurement on megaproject sustainability.

$$
\begin{gathered}
M S_{i}=\sum_{\substack{j \in[1,3] \\
k \in[1,3]}} M S_{j, k} \\
M R_{i}=\prod_{j, k=1}^{3} M R_{j, k}
\end{gathered}
$$


TABLE 8 | A scenario-based comparison on ETA.

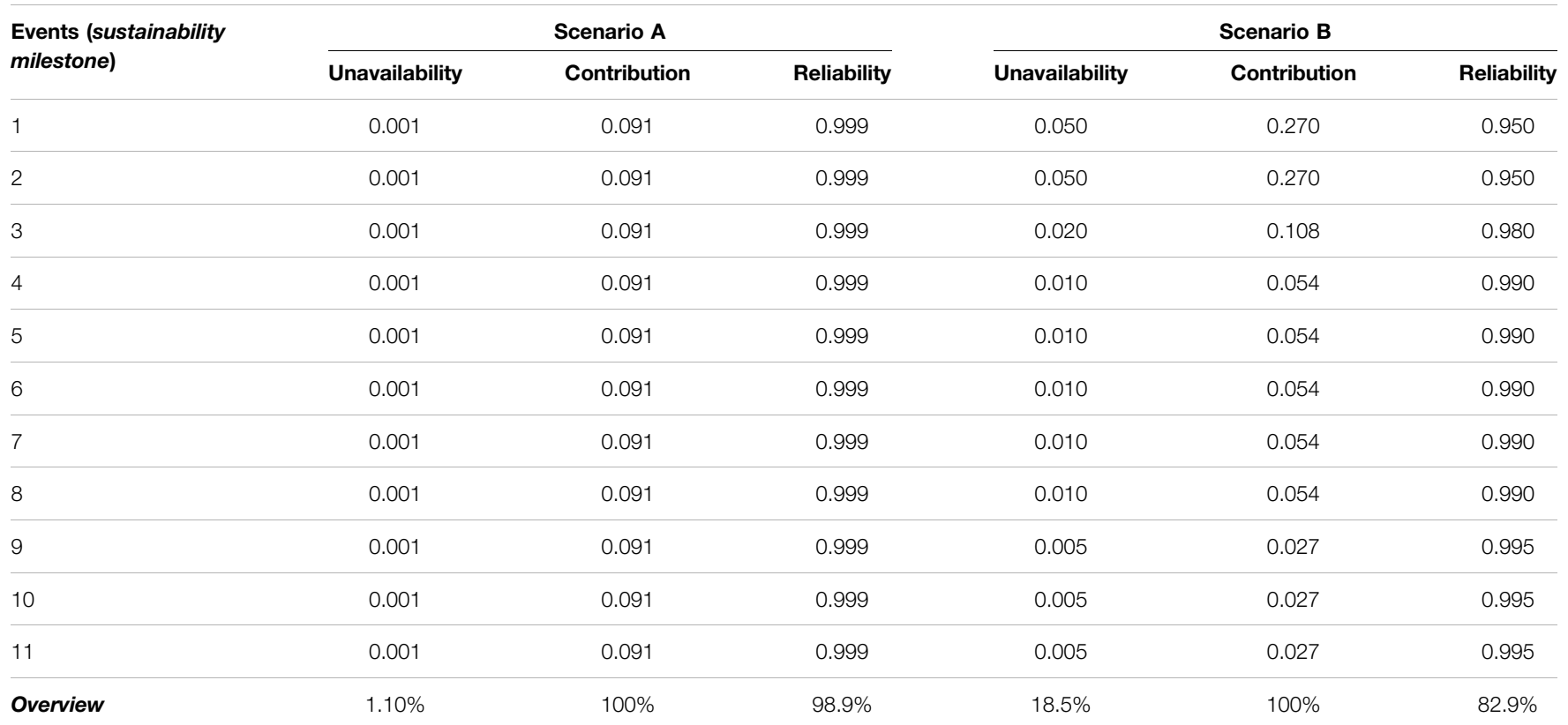

Notes: 1. The unavailability of an event is based on scenarios. The entire value to form an overview of unavailability was generated by using the Minimal Cut Sets method from the TopEvent FTA software. 2. The contribution and its figures were generated from the event tree diagram (see Figure 3) in the TopEvent FTA software. 3. The reliability of each event was converted against its unavailability, and the entire value to form an overview of reliability was derived by using Eq. 2.

- $M S_{j, k}$ represents the sustainability score of outcomes from task $j$ at time period $k$. The scale of a subscore can be either $[0,10]$ or $[0,100]$.

- $M R_{j, k}$ represents the reliability (\%) to achieve sustainability goal upon milestone $i$ in relation to task $j$ at time period $k$. The scale of each reliability value is a decimal within interval $[0,1]$ and can be converted to a percentage.

- $j$ represents the sequence number of tasks toward sustainability milestone $i$. The scale of task numbers is an integer within interval $[1,3]$ indicating all three tasks under each milestone.

- $k$ represents the sequence number of time period toward sustainability milestone $i$. The scale of the number of time periods is an integer within interval $[1,3]$ indicating all three time periods under each milestone.

A scenario-based experiment was then conducted to perform an event tree analysis (ETA) to demonstrate the proposed measurement of system reliability in the entire process toward megaproject sustainability. Two scenarios were set up with regard to how well a sustainability milestone could be achieved across 11 events, which are connected with the 11 sustainability milestones illustrated in Figure 3. As the purpose of this experiment is to demonstrate how system reliability as a new measurement can be added in MAS, the value of unavailability is given without specific physical contexts in connection with the five gates to megaproject sustainability. However, all unavailability values among the two scenarios, that is, two different megaprojects or two different packages for one megaproject, were made sensible under assumptions that particular value of unavailability could be the case in a real megaproject. Table 8 gives a summary of this experiment.
It has been noticed in comparing differences under the two scenarios in this experiment that, with regard to the contributions of all the 11 events toward megaproject sustainability, the following observations can be useful to inform further research into megaproject sustainability alongside the described research roadmap:

- The reliability (\%) can be used to quantitatively measure megaproject sustainability in terms of its status upon either project delivery or research effort driven by related goals and tasks.

- ETA is a useful tool to incorporate system reliability analysis into probabilistic risk assessment on megaproject sustainability.

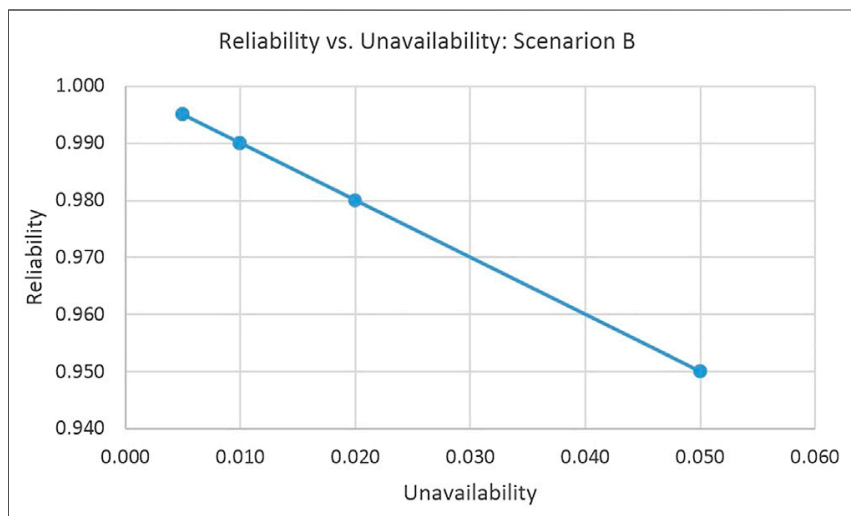

FIGURE 4 | The negative correlation between reliability and unavailability. 


\begin{tabular}{|c|c|c|c|c|c|c|c|c|c|c|}
\hline 0.100 & 0.099 & 0.098 & 0.087 & 0.096 & 0.095 & 0.094 & 0.093 & 0.092 & 0.091 & 0.090 \\
\hline 0.101 & 0.064 & 0.063 & 0.062 & 0.061 & 0.060 & 0.059 & 0.058 & 0.057 & 0.056 & 0.089 \\
\hline 0.102 & 0.065 & 0.036 & 0.035 & 0.034 & 0.033 & 0.032 & 0.031 & 0.030 & 0.055 & 0.088 \\
\hline 0.103 & 0.066 & 0.037 & 0.016 & 0.015 & 0.014 & 0.013 & 0.012 & 0.029 & 0.054 & 0.087 \\
\hline 0.104 & 0.067 & 0.038 & 0.017 & 0.004 & 0.003 & 0.002 & 0.011 & 0.028 & 0.053 & 0.086 \\
\hline 0.105 & 0.068 & 0.039 & 0.018 & 0.005 & 0.000 & 0.001 & 0.010 & 0.027 & 0.052 & 0.085 \\
\hline 0.106 & 0.069 & 0.040 & 0.019 & 0.006 & 0.007 & 0.008 & 0.009 & 0.026 & 0.051 & 0.084 \\
\hline 0.107 & 0.070 & 0.041 & 0.020 & 0.021 & 0.022 & 0.023 & 0.024 & 0.025 & 0.050 & 0.083 \\
\hline 0.108 & 0.071 & 0.042 & 0.043 & 0.044 & 0.045 & 0.046 & 0.047 & 0.048 & 0.049 & 0.082 \\
\hline 0.109 & 0.072 & 0.073 & 0.074 & 0.075 & 0.076 & 0.077 & 0.078 & 0.079 & 0.080 & 0.081 \\
\hline 0.110 & 0.111 & 0.112 & 0.113 & 0.114 & 0.115 & 0.116 & 0.117 & 0.118 & 0.119 & 0.120 \\
\hline
\end{tabular}

FIGURE 5 | Gann's square of nine (Mikula, 2003) for determining the unavailability.

Box 1| The Chunrong-Minggao sequence of thousandths.

$\{0,1,2,3,4,5,6,7,8,10,12,14,16,18,20,22,24,27,30,33,36,39,42,45,48,52,56,60,64,68,72,76,80,85,90$, $95,100,105,110,115,120\}$

Notes: 1 . This finite sequence is named after the first author's parents who are mathematicians dedicating to secondary and higher education respectively in Tsingtao, China. 2. The interval of thousandths within the finite sequence presented here is $[0.000,0.120]$.

TABLE 9 | Sequences of thousandths to determine unavailability upon megaproject sustainability.

\begin{tabular}{|c|c|c|c|}
\hline $\begin{array}{l}\text { Sequence of optimistic } \\
\text { unavailability }(\% \circ)\end{array}$ & $\begin{array}{l}\text { Sequence of pessimistic } \\
\text { unavailability }(\% \circ)\end{array}$ & Sequence of the most likely unavailability (\%o) & Expected unavailability (\%o) \\
\hline$\{0,1,2,3,4,5,6,7,8\}$ & $\{100,105,110,115,120\}$ & $\begin{array}{l}\{10,12,14,16,18,20,22,24,27,30,33,36,39,42,45,48,52,56 \\
60,64,68,72,76,80,85,90,95\}\end{array}$ & To be jointly decided by experts \\
\hline
\end{tabular}

- For each event, which can represent either practical activity or research task, there is a negative correlation (see Figure 4) between its reliability and its failure or fault to achieve sustainability goal at strategic, tactic, or operational level. Therefore, it is essential to increase the reliability of an event to keep the reliability of a lifecycle megaproject system at a proper level.

- The system reliability of megaproject sustainability can drop significantly when the values of individual event reliability decrease.

- The reliability of each event needs to be precisely defined by considering characteristics of proposed tasks in research and development for megaproject sustainability.

- The reliability value is dynamic in the process of research and practices for megaproject and needs to be adjusted.

Scenarios. It was of consideration regarding the practical implications of this ETA experiment as described above to demonstrate the relevance and usefulness of reliability assessment theory on megaproject sustainability study, and this consideration focused on the connection between the scenarios made in the ETA experiment and individual unavailability/contribution at work stages in megaproject delivery. To facilitate the use of ETA for reliability assessment on megaproject sustainability, Gann's square of nine (Mikula, 2003) was adopted to determine possible unavailability rates, which are highlighted in Figure 5. Those identified unavailability rates were then collected to establish a new sequence of thousandths (see Box 1) to facilitate a joint subjective judgment process by using three scopes of unavailability rates, which are described in Table 9, to determine the unavailability upon megaproject sustainability. Based on these considerations, Table $\mathbf{1 0}$ gives a summary of suggestions for subjective judgment within the interval of unavailability rates between $0.000 \%$ and $0.050 \%$, which is the scope of unavailability rates adopted for scenarios A and B in this ETA experiment. Tables 11 and 12 further provide assumptions about unavailability rates adopted for the two scenarios as shown in Table $\mathbf{8}$ and Figure $\mathbf{3}$ in this ETA experiment.

\section{CONCLUSION}

\section{Highlights}

This article describes findings from a recent research into megaproject sustainability in the context of a research 
TABLE 10 | Table of unavailability upon megaproject sustainability.

\begin{tabular}{|c|c|}
\hline $\begin{array}{l}\text { Unavailability } \\
\text { scale }\end{array}$ & Suggestion for subjective judgment* \\
\hline 0.000 & $\begin{array}{l}\text { Full availability to support the sustainability goal at one specific } \\
\text { work stage. }\end{array}$ \\
\hline 0.001 & Very high availability with $1 \%$ chance of failure toward the goal. \\
\hline 0.002 & Very high availability with $2 \%$ chance of failure toward the goal. \\
\hline 0.003 & $\begin{array}{l}\text { Moderate higher availability with } 3 \% \text { chance of failure toward the } \\
\text { goal. }\end{array}$ \\
\hline 0.004 & Slight higher availability with $4 \%$ chance of failure toward the goal. \\
\hline 0.005 & High availability with $5 \%$ o chance of failure toward the goal. \\
\hline 0.006 & Low availability with $6 \%$ chance of failure toward the goal. \\
\hline 0.007 & Slight lower availability with $7 \%$ o chance of failure toward the goal. \\
\hline 0.008 & $\begin{array}{l}\text { Moderate low availability with } 8 \% \text { chance of failure toward the } \\
\text { goal. }\end{array}$ \\
\hline 0.009 & $\begin{array}{l}\text { Moderate lower availability with } 9 \% \text { chance of failure toward the } \\
\text { goal. }\end{array}$ \\
\hline 0.010 & Poor availability with $1 \%$ chance of failure toward the goal. \\
\hline 0.020 & Poor availability with $2 \%$ chance of failure toward the goal. \\
\hline 0.030 & Poor availability with $3 \%$ chance of failure toward the goal. \\
\hline 0.040 & Poor availability with $4 \%$ chance of failure toward the goal. \\
\hline 0.050 & lure toward the goal. \\
\hline
\end{tabular}

Note: Although it is widely accepted that limited subjective judgments must be made regarding the estimator to use, confidence level, and so forth in reliability assessment (Martz, 2003), this table is proposed as an alternative to use experts' knowledge under the circumstance where there is currently a lack of data to form objective judgment on either megaproject sustainability or the sustainability of STEEP items in the context of the built environment.

roadmap, MAS, and reliability analysis. It established a TRIZdriven literature review amid related areas to form the structure of MSBOK and developed a research roadmap with milestones and reliability assessment for megaproject sustainability. These efforts have been made to support further research and development that explore interconnected and integrative ways to quantitatively measure STEEP issues relating to megaproject delivery across individual work stages, and therefore the whole-life sustainability and its reliability in megaproject delivery can be measured. In addition, the concept and measurement of the system reliability of megaproject sustainability have been put forward and incorporated into the described research, which has made it possible to detect how well the individual and overall sustainability goals could have been achieved among megaproject lifecycle processes. All the research outcomes described in this article were based on TRIZ-guided EBL and the authors' long-term experiences and observations in relevant research and practices in megaprojects.

It is expected that the research described in this article can be recognized valuable in terms of a good contribution to the megaproject management body of knowledge. In particular, research findings can be useful to advance continuous research and development for reliable megaproject sustainability and its assessment, to enhance the reliability of megaproject sustainability, and to support well-informed decision-making across megaproject work stages toward sustainability goals.

As a study on research roadmap, the described research in this article has yielded useful outcomes that can inform the development of a professional guidance on megaproject sustainability, and this guidance can consist of a series of relevant technical issues, which have been described in this article, including the research roadmap toward megaproject sustainability, the structure of MSBOK, the methodology of MAS, and the reliability of megaproject sustainability.

\section{Limitations}

This article describes the research and its outcomes at the strategic level only and based on some theoretical assumptions. With regard to anticipated megaproject sustainability, the research described here has limited explorations to establish an entire methodology with detailed guidance and a series of related business cases to foster research and development for the best practices. The current research outcomes described in this article were based on limited multiple source verification, although there are relevant experiences and observations, which are combined for more than 100 years, from the authors to support their subjective judgment and assumptions. In addition, the experiment on reliability assessment was based on scenarios only to which specific case studies can be incorporated in the future so as to better inform further research and professional practices.

\section{Remarks}

In addition to the usefulness of research outcomes to develop individual research tasks, which include a novel evidence base, the described research roadmap can support a new research cluster to foster research into the assessment and enhancement of megaproject sustainability within BIM pervasive project environment (Chen et al., 2020).

Based on what has been achieved from the described research here, further efforts can be made to improve the research roadmap through a validation process based on peer review so that professional guidance could be eventually developed for best practices on megaproject sustainability.

It is an important implication from the research roadmap described in this article that the pursuit of megaproject sustainability at various work stages needs to add the adaption to environmental dynamics on the agenda. While this article does not make it specific regarding how the STEEP issues could be dealt with, EBL has been highlighted to make the described research roadmap generic and clear at the strategic level. It is therefore necessary in the adoption of the described research roadmap to include specific EBL from research and practices in related areas. For example,

- at the planning stage, the location selection of megaprojects such as transport megaproject (Chen et al., 2011; NASEM, 
TABLE 11 | Unavailability upon megaproject sustainability in the ETA experiment: Scenario A.

\begin{tabular}{|c|c|c|c|}
\hline ETA event & Sustainability milestone & $\begin{array}{l}\text { U/A } \\
\text { rate }\end{array}$ & Assumption according to Table 10 \\
\hline \multicolumn{4}{|l|}{ Scenario A } \\
\hline 1 & M1.1 Assessment of strategy & 0.001 & Very high availability with $1 \%$ chance of failure toward the sustainability goal at the strategy stage. \\
\hline 2 & M1.2 Assessment of preparation and brief & 0.001 & Very high availability with $1 \%$ o chance of failure toward the sustainability goal at the preparation stage. \\
\hline 3 & M2.1 Concept design assessment & 0.001 & Very high availability with $1 \%$ chance of failure toward the sustainability goal at the concept design stage. \\
\hline 4 & M2.2 Developed design assessment & 0.001 & Very high availability with $1 \%$ chance of failure toward the sustainability goal at the developed design stage. \\
\hline 5 & M2.3 Technical design assessment & 0.001 & Very high availability with $1 \%$ chance of failure toward the sustainability goal at the technical design stage. \\
\hline 6 & M3.1 Assessment of construction & 0.001 & Very high availability with $1 \%$ chance of failure toward the sustainability goal at the construction stage. \\
\hline 7 & M3.2 Assessment of handover & 0.001 & Very high availability with 1\% chance of failure toward the sustainability goal at the handover stage. \\
\hline 8 & M4.1 Assessment of operation & 0.001 & Very high availability with $1 \%$ chance of failure toward the sustainability goal at the operation stage. \\
\hline 9 & M4.2 Assessment of maintenance & 0.001 & Very high availability with $1 \%$ chance of failure toward the sustainability goal at the maintenance stage. \\
\hline 10 & M5.1 Assessment of decommission & 0.001 & Very high availability with $1 \%$ chance of failure toward the sustainability goal at the decommission stage. \\
\hline 11 & M5.2 Assessment of recommission & 0.001 & $y$ high availability with $1 \%$ chance of failure toward the sustainability goal at the recommission stage. \\
\hline
\end{tabular}

TABLE 12 | Unavailability upon megaproject sustainability in the ETA experiment: Scenario B.

\begin{tabular}{|c|c|c|c|}
\hline ETA event & Sustainability milestone & U/A rate & Assumption according to Table 10 \\
\hline \multicolumn{4}{|l|}{ Scenario B } \\
\hline 1 & M1.1 Assessment of strategy & 0.050 & Poor availability with 5\% chance of failure toward the sustainability goal at the strategy stage. \\
\hline 2 & M1.2 Assessment of preparation and brief & 0.050 & Poor availability with $5 \%$ chance of failure toward the sustainability goal at the preparation stage. \\
\hline 3 & M2.1 Concept design assessment & 0.020 & Poor availability with $2 \%$ chance of failure toward the sustainability goal at the concept design stage. \\
\hline 4 & M2.2 Developed design assessment & 0.010 & Poor availability with $1 \%$ chance of failure toward the sustainability goal at the developed design stage. \\
\hline 5 & M2.3 Technical design assessment & 0.010 & Poor availability with $1 \%$ chance of failure toward the sustainability goal at the technical design stage. \\
\hline 6 & M3.1 Assessment of construction & 0.010 & Poor availability with $1 \%$ chance of failure toward the sustainability goal at the construction stage. \\
\hline 7 & M3.2 Assessment of handover & 0.010 & Poor availability with $1 \%$ chance of failure toward the sustainability goal at the handover stage. \\
\hline 8 & M4.1 Assessment of operation & 0.010 & Poor availability with $1 \%$ chance of failure toward the sustainability goal at the operation stage. \\
\hline 9 & M4.2 Assessment of maintenance & 0.005 & High availability with $5 \%$ chance of failure toward the sustainability goal at the maintenance stage. \\
\hline 10 & M5.1 Assessment of decommission & 0.005 & High availability with $5 \%$ chance of failure toward the sustainability goal at the decommission stage. \\
\hline 11 & M5.2 Assessment of recommission & 0.005 & High availability with $5 \%$ o chance of failure toward the sustainability goal at the recommission stage. \\
\hline
\end{tabular}

2016) and industrial megaproject (Chen et al., 2008; Merrow, 2011);

- at the construction stage, the health and safety management such as the control of the spread of severe acute respiratory syndrome coronavirus 2 (SARS-CoV-2) on the Tseung Kwan O-Lam Tin (TKO-LT) Tunnel project (CEDD, 2020);

- at the operation stage, the dependability of services provision such as the maintenance of air quality in London Underground (Hodgson et al., 2019) and the disinfection of SARS-CoV-2 in New York City subways (Loud, 2020); and

- across multiple work stages, the protection of water infrastructure from contamination (EPA, 2020).

In response to grand challenges in megaproject delivery (Chen, 2019), further research alongside the research roadmap toward megaproject sustainability needs to tackle the dynamic interactions among the built, the natural, and the social environment to achieve the harmony in a longer term. 


\section{DATA AVAILABILITY STATEMENT}

The original contributions presented in the study are included in the article, further inquiries can be directed to the corresponding author.

\section{ETHICS STATEMENT}

The study presented in this article has thorough ethical considerations and involves no human or animal subject.

\section{AUTHOR CONTRIBUTIONS}

All authors listed have made a substantial, direct and intellectual contribution to the work, and approved it for publication.

\section{FUNDING}

The research described in this paper was part of COST Action TU1003 (The Effective Design and Delivery of Megaprojects in the European Union) (2011-2015), which was funded by the

\section{REFERENCES}

Aarseth, W., Ahola, T., Aaltonen, K., Økland, A., and Andersen, B. (2017). Project Sustainability Strategies: A Systematic Literature Review. Int. J. Project Management 35 (6), 1071-1083. doi:10.1016/j.ijproman.2016.11.006

Abadie, R. (2020). Global Infrastructure Trends. London, UK: PwC. doi:10.5194/ nhess-2019-225-ac2

AECOM (2016). Sustainability Report 2015. Los Angeles, USA: AECOM.

Altshuler, A. A., and Luberoff, D. E. (2003). Mega-Projects: The Changing Politics of Urban Public Investment. USA: Brookings Institution Press.

Arup (2013). Research Roadmap 2013. London, UK: Arup.

Arup (2012). SPeAR ${ }^{\circledR}$ Handbook 2012. London, UK: Arup.

Bamberger, M., and Cheema, G. S. (1990). Case Studies of Project Sustainability: Implications for Policy and Operations from Asian Experience. Washington, D.C., USA: Economic Development Institute (EDI), World Bank Group. doi:10. 1596/0-8213-1614-1

Bechtel (2016). Sustainability Report 2015. San Francisco, USA: Bechtel Corporation.

Boateng, P., Chen, Z., and Ogunlana, S. O. (2017). Megaproject Risk Analysis and Simulation: A Dynamic Systems Approach. UK: Emerald Group Publishing Limited. doi:10.1108/9781786358301

Boateng, P., Chen, Z., and Ogunlana, S. O. (2015). An Analytical Network Process Model for Risks Prioritisation in Megaprojects. Int. J. Project Management 33 (8), 1795-1811. doi:10.1016/j.ijproman.2015.08.007

BRE (2016). BREEAM International New Construction 2016: Technical Manual. UK: BRE Global Ltd.

BSRIA (2015). BIM Roadmap - a Building Owners' Guide to Implementing BIM, Building Applications Guide BG 60/2015. UK: BSRIA Limited.

Carillion (2016). Sustainability Report 2015. Wolverhampton, UK: Carillion plc. CEDD (2020). Tseung Kwan O-Lam Tin (TKO-LT) Tunnel: What's New. Hong Kong, China: Civil Engineering and Development Department (CEDD), HKSAR Government.

Chen, Z., Abdullah, A. B., Anumba, C. J., and Li, H. (2014). An ANP Experiment for Demolition Plan Evaluation. J. Constr. Eng. Manage. 140 (2), 06013005. doi:10.1061/(ASCE)CO.1943-7862.0000791

Chen, Z., and Agapiou, A. (2017). A Research Roadmap for Megaproject Sustainability Assessment. In Proceedings of International Research Conference, 11-12/09/2017,
European Cooperation in Science and Technology (COST) under the EU Framework Programme Horizon 2020.

\section{ACKNOWLEDGMENTS}

The authors of this article would like to acknowledge the contributions and/or support from colleagues in peer reviews and production prior to the publication. Part of the research described in this article was presented at the International Research Conference 2017: Shaping Tomorrow's Built Environment, which was in conjunction with $\mathrm{CIB}$, and chaired by Professor Hisham Elkadi at the University of Salford and Professor Les Ruddock at the University of Huddersfield. This article is prepared for the Research Topic on "Reviews for Advanced Construction Management" at the journal Frontiers of Built Environment. The launch of this Research Topic is a unique opportunity that aided the authors' efforts to further explore the use of TRIZ for evidence-based learning with regard to in-depth review in a systemic way for research into construction management, especially for megaproject delivery. The experiment on ETA was conducted by using the TopEvent FTA software provided by Reliotech.

University of Salford, Salford, UK. International Council for Research and Innovation in Building and Construction (CIB), 106-117.

Chen, Z., Agapiou, A., and Li, H. (2020). A Benefits Prioritization Analysis on Adopting BIM Systems against Major Challenges in Megaproject Delivery. Front. Built Environ. 6, 26. doi:10.3389/fbuil. 2020.00026

Chen, Z. (2010). ANP Models and STEEP Criteria. In Proceedings of ARCOM Doctoral Research Workshop on Decision Making, 10/02/2010. Manchester, UK: University of Manchester, 46-56.

Chen, Z., Boateng, P., and Ogunlana, S. O. (2019). A Dynamic System Approach to Risk Analysis for Megaproject Delivery. Proc. Inst. Civil Eng. - Manag. Procurement L. 172 (6), 232-252. doi:10.1680/jmapl.18.00041

Chen, Z., Clements-Croome, D. J., Li, H., Shen, G. Q. P., and Chung, J. K. H. (2007). A TRIZ Based ANP Approach to Value Management in Façades Assessment. The Value Manager 13 (2), 3-8.

Chen, Z. (2018). Editorial. Proc. Inst. Civil Eng. - Eng. Sustainability 171 (8), 381-382. doi:10.1680/jensu.2018.171.8.381

Chen, Z., Glass, J., Hobbs, G., and McCormick, S. (2017). Themed Issue on BIM for Waste and Resource Management: Call for Papers. Proceedings of the Institution of Civil Engineers - Waste and Resource Management. doi:10. 13140/RG.2.2.36567.68005

Chen, Z. (2019). Grand Challenges in Construction Management. Front. Built Environ. 5, 31. doi:10.3389/fbuil.2019.00031

Chen, Z., and Khumpaisal, S. (2009). An Analytic Network Process for Risks Assessment in Commercial Real Estate Development. J. Property Invt. Finance 27 (3), 238-258. doi:10.1108/14635780910951957

Chen, Z., and Li, H. (2006). Environmental Management in Construction: A Quantitative Approach. London and New York: Taylor \& Francis.

Chen, Z., Li, H., Ren, H., Xu, Q., and Hong, J. (2011). A Total Environmental Risk Assessment Model for International Hub Airports. Int. J. Project Management 29 (7), 856-866. doi:10.1016/j.ijproman.2011.03.004

Chen, Z., Li, H., Xu, Q., and Sun, S.-L. (2008). "The Disaster-Oriented Assessment of Urban Clusters for Locating Production Systems in China," In Encyclopedia of Decision Making and Decision Support Technologies. Editors F. Adam and P. Humphreys (Hershey, PA, United States: Idea Group Inc), 253-271. doi:10.4018/978-1-59904-8437.ch030 
Chen, Z. (2007). Multicriteria Decision-Making for the Sustainable Built Environment. Reading, UK: University of Reading.

Chen, Z. (1995). Reliability Analysis of Network Planning in Construction (In Chinese). J. Qingdao Univ. Technology 16 (1), 18-22.

Chen, Z. (2017). The Principles of Facilities Management and Case Studies. In Proceedings of Doctoral Workshop in Building Asset Management, Association of Researchers in Construction Management (ARCOM), 21/01/2017. Glasgow, UK: Glasgow Caledonian University. doi:10.1061/9780784481066.008

CIE (2016). Research Roadmap for Healthful Interior Lighting Applications. Vienna, Austria: International Commission on Illumination (CIE).

Clipson, C. W., and Johnson, R. E. (1987). Integrated Approaches to Facilities Planning and Assessment. Plann. Higher Education 15 (3), 12-22.

Cranney, J., and McDonald, F. (2012). "Evidence-Based Learning," in Encyclopedia of the Sciences of Learning. Editor N. M. Seel (Springer), 1185-1188. doi:10. 1007/978-1-4419-1428-6_767

DTI (2007). Roadmap for the Development of Intelligent Monitoring of Concrete Structures. London, UK: Department of Trade and Industry (DTI).

EPA (2020). Homeland Security Research: Water Infrastructure Decontamination. Washington, DC, USA: Environmental Protection Agency (EPA).

Flyvbjerg, B. (2017). The Oxford Handbook of Megaproject Management. UK: Oxford University Press. doi:10.1093/oxfordhb/9780198732242.013.8

Gadd, K. (2011). TRIZ for Engineers: Enabling Inventive Problem Solving. Oxford, UK: John Wiley \& Sons. doi:10.1002/9780470684320

Gijzel, D., Bosch-Rekveldt, M., Schraven, D., and Hertogh, M. (2020). Integrating Sustainability into Major Infrastructure Projects: Four Perspectives on Sustainable Tunnel Development. Sustainability 12 (1), 6. doi:10.3390/su12010006

Greiman, V. A. (2013). Megaproject Management: Lessons on Risk and Project Management from the Big Dig. USA: John Wiley \& Sons. doi:10.1002/9781118671092

Haezendonck, E., and Van den Berghe, K. (2020). Patterns of Circular Transition: What Is the Circular Economy Maturity of Belgian Ports? Sustainability 12 (21), 9269. doi:10.3390/su12219269

Hart, L. (2015). Procuring Successful Mega-Projects: How to Establish Major Government Contracts without Ending up in Court. UK: Routledge.

Hodgson, C., Hook, L., and Bernard, S. (2019). November 5). London Underground: The Dirtiest Place in the City. London, UK: Financial Times. Available at: https://www.ft.com/content/6f381ad4-fef7-11e9-be59-e49b2a136b8d.

HS2 (2016). Annual Report and Accounts 2015/16. UK: High Speed Two Ltd.

ICCPM (2011). Complex Project Management: Global Perspectives and the Strategic Agenda to 2025. Deakin West, Australia: International Centre for Complex Project Management (ICCPM).

IPA (2016). Government Construction Strategy 2016-20. London, UK: Infrastructure and Projects Authority (IPA).

IPA (2020). Proposal for A New Approach to Building: Call for Evidence - Summary of Evidence. London, UK: Infrastructure and Projects Authority (IPA).

IPMA (2011). Project Perspectives 2011. Amsterdam, Netherlands: International Project Management Association (IPMA).

Khatiwada, L. K. (2017). Implementing a Post-Project Sustainability Study (PSS) of a Development Project: Lessons Learned from Indonesia. Reconsidering Development, 5 (1). Available at: https://pubs.lib.umn.edu/index.php/ reconsidering/article/view/904.

Kovner, A. R., and Rundall, T. G. (2006). Evidence-based Management Reconsidered. Front. Health Serv. Manage. 22 (3), 3-22. doi:10.1097/ 01974520-200601000-00002

Laprise, M., Lufkin, S., and Rey, E. (2015). An Indicator System for the Assessment of Sustainability Integrated into the Project Dynamics of Regeneration of Disused Urban Areas. Building Environ. 86, 29-38. doi:10.1016/j.buildenv.2014.12.002

Lee, S.-W., and Jeon, J.-K. (2018). Dynamic Relationships between Mega Projects and Official Development Assistance: Case of South Korean Infrastructure Construction Projects in ASEAN's Developing Countries. Sustainability 10 (12), 4491. doi:10.3390/su10124491

Loud, N. (2020). MTA Expands Program Using UV Light to Kill COVID-19 on NYC Subway Cars. Untapped New York. Available at: https://untappedcities.com/2020/ 06/17/mta-expands-program-using-uv-light-to-kill-covid-19-on-nyc-subway-cars/.

Mansell, P., Philbin, S. P., and Konstantinou, E. (2020). Redefining the Use of Sustainable Development Goals at the Organisation and Project Levels-A Survey of Engineers. Administrative Sci. 10 (3), 55. doi:10.3390/admsci10030055
Martens, M. L., and Carvalho, M. M. (2016). The Challenge of Introducing Sustainability into Project Management Function: Multiple-Case Studies. J. Clean. Prod. 117, 29-40. doi:10.1016/j.jclepro.2015.12.039

Martz, H. F. (2003). "Reliability Theory," in Encyclopedia of Physical Science and Technology. Editor R. A. Meyers. Third Edition (Cambridge, Massachusetts, USA: Academic Press), 143-159. 9780122274107. doi:10.1016/B0-12-227410-5/00659-1

McNaughton, A., Dalton, G., Davies, A., Holland-Kaye, J., Hou, T., Boyd, E. H., et al. (2020). A Systems Approach to Infrastructure Delivery: A Review of How Systems Thinking Can Be Used to Improve the Delivery of Complex Infrastructure Projects. London, UK: Institution of Civil Engineers.

Merrow, E. M. (2011). Industrial Megaprojects: Concepts, Strategies, and Practices for Success. USA: John Wiley \& Sons. doi:10.4043/21858-ms

Mikula, P. (2003). The Definitive Guide to Forecasting Using W.D. Gann's Square of Nine. Austin, TX, USA: Mikula Forecasting Company.

Morfaw, J. (2014). Fundamentals of Project Sustainability Paper Presented at PMI $^{\circledR}$ Global Congress 2014, North America, Phoenix, AZ. Newtown Square, PA, USA: Project Management Institute (PMI).

National Academies of Sciences, Engineering, and Medicine (NASEM) (2016). Addressing Significant Weather Impacts on Airports: Quick Start Guide and Toolkit. Washington, DC: The National Academies Press. doi:10.17226/ 23629

OED (1988). Project Performance Results for 1986. Washington, DC, USA: Operations Evaluation Department (OED), The World Bank Group.

Priemus, H., and Van Wee, B. (2013). International Handbook on Mega-Projects. UK: Edward Elgar. doi:10.4337/9781781002308

Pryke, S. (2019). Successful Construction Supply Chain Management: Concepts and Case Studies. 2nd Edition. Oxford, UK: John Wiley \& Sons.

RIBA (2013). Guide to Using the RIBA Plan of Work 2013. London, UK: RIBA Publishing Ltd.

RIBA (2020). RIBA Plan of Work 2020 Overview. London, UK: RIBA Publishing Ltd. doi:10.4324/9781003106333

Roaf, S., Horsley, A., and Gupta, R. (2003). Closing the Loop: Benchmarks for Sustainable Buildings. UK: RIBA Enterprises. doi:10.1093/gao/9781884446054. article.t010213

Sarkheyli, E., Rafieian, M., and Taghvaee, A. A. (2016). Qualitative Sustainability Assessment of the Large-Scale Redevelopment Plan in Samen District of Mashhad. Int. J. Architecture Urban Development 6 (2), 49-58.

Skanska (2016). Skanska Sustainability Report 2015. Sweden: Skanska AB.

Suárez, J. J., Callahan, A. M., and Lichtenstein, J. E. (2012). Achieving Superior Delivery of Capital Projects: Accenture Global Survey of the Metals and Mining Industries. Toronto, Canada: Accenture.

The Crown Estate (2016). The Crown Estate Annual Report and Accounts 2015/16. London: The Crown Estate.

Wang, T., He, Q., Lu, Y., and Yang, D. (2018). How Does Organizational Citizenship Behavior (OCB) Affect the Performance of Megaprojects? Insights from a System Dynamic Simulation. Sustainability 10 (6), 1708. doi:10.3390/su10061708

Conflict of Interest: The authors declare that the research was conducted in the absence of any commercial or financial relationships that could be construed as a potential conflict of interest.

Publisher's Note: All claims expressed in this article are solely those of the authors and do not necessarily represent those of their affiliated organizations, or those of the publisher, the editors and the reviewers. Any product that may be evaluated in this article, or claim that may be made by its manufacturer, is not guaranteed or endorsed by the publisher.

Copyright (c) 2021 Chen, Agapiou, Li and Xu. This is an open-access article distributed under the terms of the Creative Commons Attribution License (CC $B Y$ ). The use, distribution or reproduction in other forums is permitted, provided the original author(s) and the copyright owner(s) are credited and that the original publication in this journal is cited, in accordance with accepted academic practice. No use, distribution or reproduction is permitted which does not comply with these terms. 


\section{GLOSSARY}

\section{CMBOK}

This acronym stands for the Construction Management Body of Knowledge. It refers to a set of structured descriptions about professional knowledge and underpinned techniques to sustain dependable quality services of construction management at both macro and micro scale in the built environment. Please refer to article Grand Challenges in Construction Management, which was published at Frontiers in Built Environment (5:31. DOI: 10.3389/ fbuil.2019.00031) (Chen, 2019), for details about a preliminary framework of CMBOK.

\section{Evidence Based Learning (EBL)}

A method to facilitate learning from cases including those in academic research and professional practices.

\section{Megaproject}

A large-scale capital project typically costing more than USD1bn.

\section{Megaproject delivery}

The whole process to provide multidisciplinary bespoke professional services across various work stages throughout the lifecycle of megaproject. It covers all relevant acts in association with the use of resources in megaproject development and operation as well as the dynamic social and natural environment in a local area.

\section{Megaproject sustainability}

The quality of a megaproject with regard to the use of resources and the functions of its services in relation to social, technical, economic, environmental and political (STEEP) aspects/issues across all lifecycle work stages in both short and longer term. The need for substantiating sustainability in megaproject delivery can be specified by focusing on people, process and product in the context of STEEP issues. The megaproject sustainability can be measured in both qualitative and quantitative way.

\section{Multiple source verification}

A qualitative and/or quantitative approach to validation through checking and comparing targeted issue/s by using evidence collected from independent sources in the same subject area.

\section{Sustainability dynamics}

STEEP (Social, Technical, Economic, Environmental and Political) forces or processes that produce dynamic interactions inside a group or system towards sustainability goals.

\section{Reliability of sustainability}

The quality of sustainability under specified goals to be achieved in a dynamic system process driven by STEEP (Social, Technical, Economic, Environmental and Political) forces.

\section{TRIZ}

This abbreviation stands for the Russian acronym for 'Teoriya Resheniya Izobretatelskikh Zadatch' which means the 'Theory of Inventive Problem Solving' in English. 